Provided for non-commercial research and education use. Not for reproduction, distribution or commercial use.

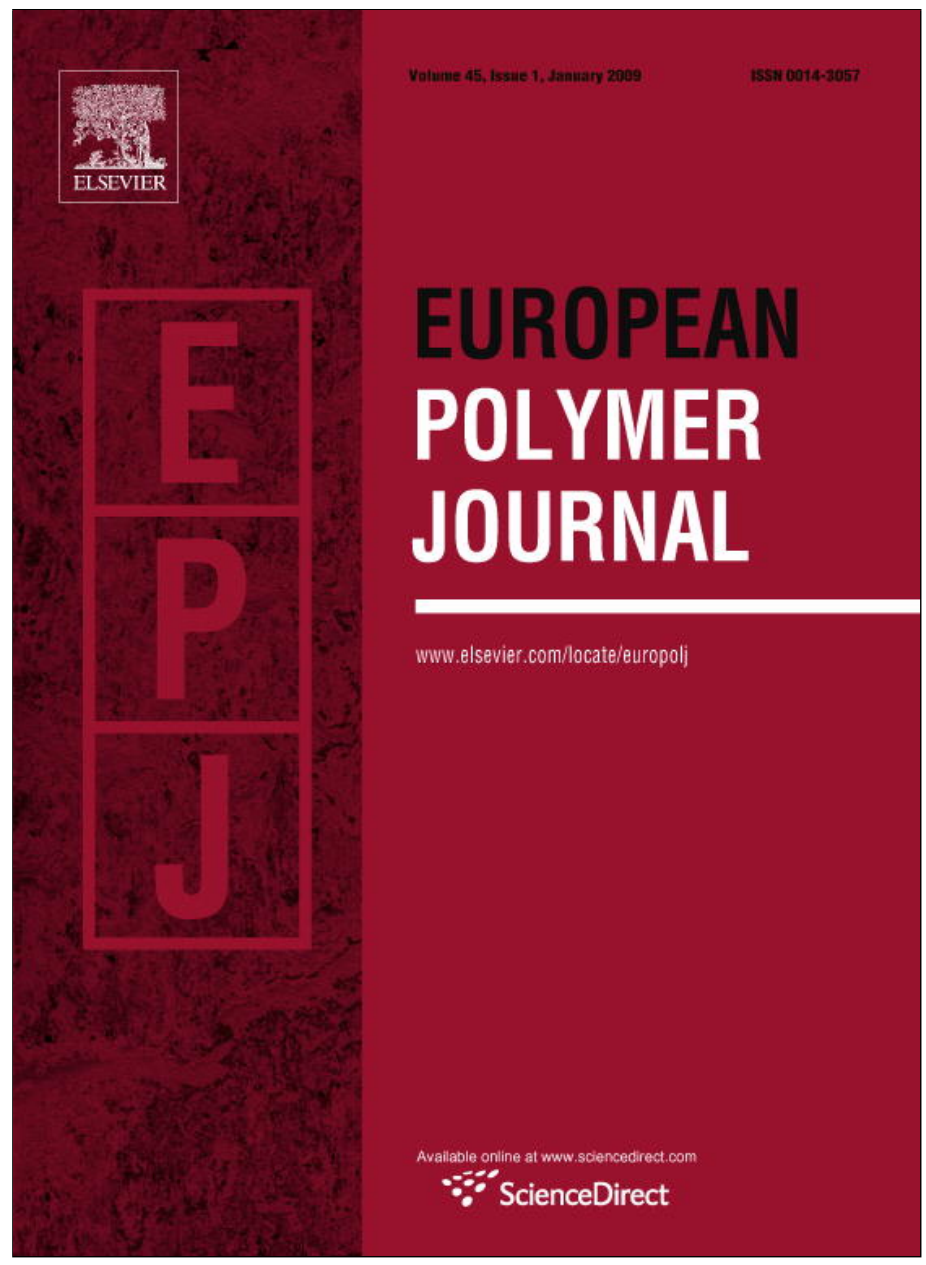

This article appeared in a journal published by Elsevier. The attached copy is furnished to the author for internal non-commercial research and education use, including for instruction at the authors institution and sharing with colleagues.

Other uses, including reproduction and distribution, or selling or licensing copies, or posting to personal, institutional or third party websites are prohibited.

In most cases authors are permitted to post their version of the article (e.g. in Word or Tex form) to their personal website or institutional repository. Authors requiring further information regarding Elsevier's archiving and manuscript policies are encouraged to visit:

http://www.elsevier.com/copyright 


\title{
Preparation of chitosan scaffolds loaded with dexamethasone for tissue engineering applications using supercritical fluid technology
}

\author{
Ana Rita C. Duarte*, João F. Mano, Rui L. Reis \\ 3B's Research Group - Biomaterials, Biodegradables and Biomimetics, University of Minho, \\ Headquarters of the European Institute of Excellence on Tissue Engineering and Regenerative Medicine, AvePark, $4806-909$ Taipas, Guimarães, Portugal ${ }^{1}$ \\ IBB - Institute for Biotechnology and Bioengineering, PT Government Associated Laboratory, Guimarães, Portugal ${ }^{2}$
}

\section{A R T I C L E I N F O}

\section{Article history:}

Received 29 July 2008

Received in revised form 25 September 2008

Accepted 6 October 2008

Available online 14 October 2008

\section{Keywords:}

Drug delivery

Scaffolds

Chitosan

Supercritical fluids

Impregnation

Dexamethasone

\begin{abstract}
A B S T R A C T
Supercritical fluid impregnation was tested to prepare a new scaffold loaded with a bioactive compound. Dexamethasone is used in osteogenic media to direct the differentiation of stem cells towards the osteogenic lineage. Dexamethasone was impregnated in chitosan scaffolds at different operating conditions, in order to optimize the impregnation process. Pressure and temperature affect the carbon dioxide density and influence the swelling of the polymer and the drug solubility in the fluid phase, therefore these are two important parameters that were studied in this work. Chitosan sponges prepared by freeze drying were impregnated with the active compound at pressures from 8.0 up to $14.0 \mathrm{MPa}$ and temperatures from 35 up to $55^{\circ} \mathrm{C}$. The effect of the impregnation contact time ( $3 \mathrm{~h}$ and $6 \mathrm{~h}$ ) was also evaluated. From the experiments performed we can conclude that the yield of impregnation is lower when increasing pressure and temperature. The contact time will mainly influence the amount of drug impregnated in the scaffold and for higher contact times the impregnation yield is also higher. Scanning electron microscopy shows particles of dexamethasone in the bulk of the scaffold, which confirms the feasibility of the supercritical fluid impregnation technology for the preparation of delivery devices. The loading capacity of the scaffolds was determined by spectroscopic analysis and the highest loading was achieved for the experiments performed at 8.0 MPa and $35^{\circ} \mathrm{C}$. Furthermore, in vitro drug release studies were carried out and the results show that dexamethasone was sustainably released. Supercritical fluid impregnation proved to be feasible for the preparation of a drug delivery system for bone tissue engineering purposes.
\end{abstract}

(c) 2008 Elsevier Ltd. All rights reserved.

\section{Introduction}

The emerging next generation of engineered tissues relies on the development of loaded scaffolds containing bioactive molecules in order to control the cellular function (e.g. growth or differentiation factors) or to act on the surrounding tissues (e.g. drugs such as anti-inflammatory agents or antibiotics) [1,2]. Hence, the strategy is to

\footnotetext{
* Corresponding author. Fax: +351253510909.

E-mail address: aduarte@dep.uminho.pt (A.R.C. Duarte).

1 http://www.3bs.uminho.pt

2 www.ibb.pt
}

mimic matrix and provide the necessary information or signaling for cell attachment, proliferation and differentiation to meet the requirement of dynamic reciprocity for tissue engineering. This justifies the importance of drug delivery in tissue engineering applications $[3,4]$.

Drug delivery systems, due to the wide range of materials that can be processed, their various sizes and shapes as well as different administration routes, are suitable for many therapeutics applications. One ideal strategy in tissue engineering is to enable the self-healing potential of the patient to regenerate body tissue and organs $[5,6]$. This goal can be achieved if a bioactive scaffold is designed in such a manner that at the same time it provides cells a 
support to grow and also induces their differentiation and proliferation.

Small molecular weight drugs that control proliferation differentiation of cells can be incorporated into biodegradable scaffolds to induce cellular differentiation and tissue remodeling. The scaffold plays, therefore an important role not only as a physical support but also in the cell proliferation and differentiation. Dexamethasone (chemical structure presented in Fig. 1) is an interesting bioactive compound to be used in tissue engineering applications. This drug is used in osteogenic media to direct the differentiation of stem cells towards the osteogenic lineage [7-9].

Chitosan is a cationic polymer derived from chitin comprising copolymers of $\beta(1 \rightarrow 4)$-glucosamine and $\mathrm{N}$-acetyl-D-glucosamine. Chitin is a natural-origin polysaccharide that can be found in crustacean shells. The physicochemical and biological properties of chitosan make it an excellent material for the preparation of drug delivery systems and for the development of new biomedical applications in many fields from skin to bone or cartilage [10].

Chitosan has been processed in several forms to be used in tissue engineering applications, namely, membranes [11], particles [12], fibers and 3D fiber meshes [13]. Chitosan may also be used as a drug delivery carrier and various studies have been reported in literature $[14,15]$. Chitosan sponges and scaffolds are also described in literature as deliver systems able to carry active agents or biomolecules and growth factors [16]. The preparation of these systems normally envolves freeze-drying or lyophilising a chitosan gel solution $[17,18]$. Supercritical fluid impregnation of bioactive molecules in chitosan derivatives with flurbiprofen and timolol maleate has been successfully reported in literature for ophthalmic drug delivery applications [19]. Additionally, thermo-responsive chitosan scaffolds processed by means of a green technology are also described in literature as smart partially-biodegradable scaffolds for tissue engineering applications [20].

Conventional impregnation consists on the immersion a polymeric matrix in a solution, which can be organic or aqueous, where the $\operatorname{drug}(\mathrm{s})$ have been previously dissolved. However this method presents several disadvantages, such as the use of toxic organic solvents, which have to be removed and add a drying step to the drug device processing. Further, this drying step can include heating, which can degrade thermolabile substances.

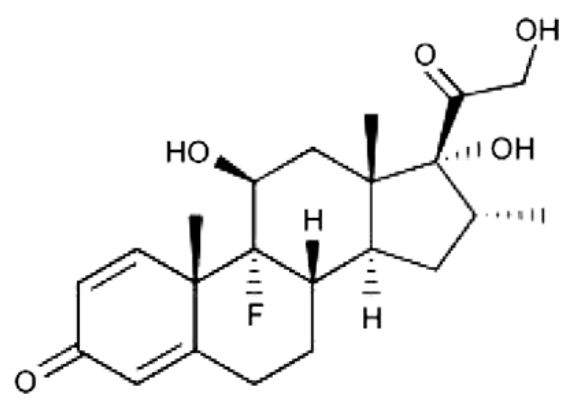

Fig. 1. Chemical structure of dexamethasone.
The preparation of drug release products requires the use of a mobile phase able to dissolve and carry the drug component, that can also swell and stretch the polymer matrix, facilitating the diffusion of the drug and increasing the rate of impregnation.

Impregnation using supercritical fluid technology has proven to be feasible when the pharmaceutical compound is soluble in carbon dioxide and the polymer can be swollen by the supercritical fluid $[21,22]$. A high purity product, free of residual solvents is obtained, since no organic solvents are involved in the impregnation process. Supercritical fluids, especially supercritical carbon dioxide $\left(\mathrm{scCO}_{2}\right)$ have been identified as prime candidates to develop alternative clean processes for the preparation of drug-loaded polymeric matrixes [23]. Furthermore, the use of supercritical fluids can take advantage of their high diffusivity in polymers, in combination with the high solubility and plasticizing action. Therefore, compressed $\mathrm{CO}_{2}$ can be used as a solvent to carry the drug into biocompatible polymers even if they are processed in complex shapes. Moreover, when depressurisation occurs, the gas rapidly diffuses out of the polymer, deplasticizing it and warranting the complete removal of solvent, without exposing polymers and drugs to high temperatures, which may degrade them [24,25].

In this work the possibility of impregnating a chitosan scaffold with dexamethasone was evaluated. The effect of pressure, temperature and contact time was evaluated in order to determine the best operating conditions for the impregnation process. The loading capacity of the scaffolds as well as the release profiles of the drug out of the delivery device were evaluated and the results are presented.

\section{Experimental procedure}

\subsection{Materials}

Chitosan of medium molecular weight (degree of deacetylation $\sim 85 \%$ ), CAS [9012-76-4] was purchased from Aldrich. Dexamethasone, CAS [50-02-2], (98\% purity) and phosphate buffer saline (PBS) were purchased from Sigma. Acetic acid, CAS [64-19-7] (99.7\% purity) was purchased from Panreac. Distilled water was used. Carbon dioxide (99.5\%, industrial grade) was obtained from Air Liquide. Chitosan was previously purified using a protocol described elsewhere [26]. All the other products were used with no further purification.

\subsection{Scaffold preparation}

A solution of $4 \mathrm{wt} \%$ of chitosan in a diluted acetic acid solution ( $2 \mathrm{wt} \%$ in water) was prepared. The solution was poured into cylindrical moulds, which were froze at $-80{ }^{\circ} \mathrm{C}$ and lyophilised (Telstar-Cryodos -80 Spain) up to 4 days to completely remove the frozen solvent. Then, the scaffolds were neutralized using a $0.1 \mathrm{~m}$ sodium hydroxide solution and washed several times with distilled water, as previously described elsewhere $[27,28]$. After this procedure the samples were frozen at $-80^{\circ} \mathrm{C}$ and once again lyophilised. 


\subsection{Supercritical fluid impregnation process}

Supercritical fluid impregnation was carried out in the batch mode, as previous experiments show that this procedure gives much higher yields of impregnation than the continuous process $[29,30]$. The impregnation apparatus is schematically presented in Fig. 2.

The equipment consists basically in a high pressure reactor heated by means of a heating tape that maintains the temperature within $\pm 1{ }^{\circ} \mathrm{C}$. The temperature is measured by means of a thermocouple (WATLOW, 965 series). $\mathrm{CO}_{2}$ was liquefied through a cooling unit and compressed to the operating pressure with a pump. The fluid was preheated to the desired temperature in a heat exchanger before entering the high pressure vessel. The pressure of the system is measured with a pressure transducer (ASCO, model PR711F). The previously processed scaffold and the drug were loaded in the same vessel. Dexamethasone was placed on the left hand side of the reactor and it was separated from the polymeric matrixes with a cotton piece in order to prevent contact of the two and thus, the contamination of the surface of the scaffolds with the powder. The vessel was set at the desired operational conditions ( $T$ and $p$ ) and the impregnation took place for the predetermined period. At the end of this period, the system was slowly depressurised.

\subsection{Scaffold characterization}

\subsubsection{Scanning electron microscopy - SEM}

Dexamethasone-loaded scaffolds were frozen in liquid nitrogen and were fractured in order to observe a crosssection of the matrix. The morphology of polymer samples was analyzed and imaged by scanning electron microscopy (SEM, Oxford Inca Energy 350) after gold coating.

\subsubsection{Micro-computed tomography - micro CT}

The inner structure and porosity of the scaffolds before and after impregnation were evaluated by micro-computerized tomography using a Scanco 20 equipment (Scanco Medicals, Switzerland) with penetrative X-rays of $40 \mathrm{keV}$. The X-ray scans were acquired in high-resolution mode $(39.39 \mu \mathrm{m})$. CT Vol® (SkyScan, Belgium) was used to create a 3D model of the scaffold.

\subsection{Quantification of drug loading}

The dexamethasone-loaded scaffolds were weighed and immersed in a PBS solution $(0.01 \mathrm{M}$ phosphate buffer,

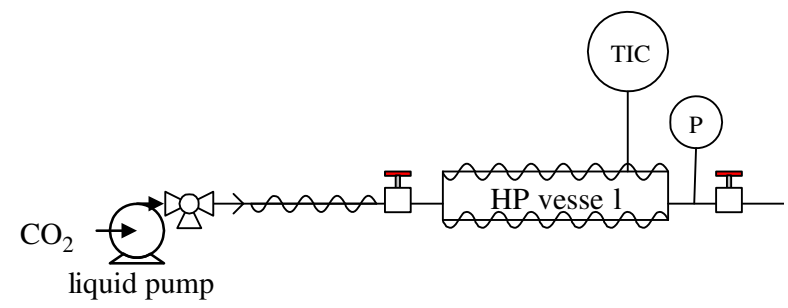

Fig. 2. Schematic diagram of the impregnation apparatus ((TIC) Temperature control, $(P)$ - pressure transducer).
$0.0027 \mathrm{M}$ potassium chloride and $0.137 \mathrm{M}$ sodium chloride, $\mathrm{pH}$ 7.4). The solution was sonicated in order to extract all the drug impregnated. In order to determine the amount of solute, the resulting solutions were analyzed by UV spectrophotometry in a UV-Vis (Shimazu UV 1601). Three loaded scaffolds impregnated under the same conditions were analyzed. Dexamethasone absorbs in the region of ultraviolet, with a maximum absorbance at $242 \mathrm{~nm}$. Calibration was obtained by using of standard samples with concentrations between (0.001 and $0.05) \mathrm{mg} / \mathrm{mL}$.

\subsection{In vitro release studies}

The scaffolds impregnated with dexamethasone were suspended in $10 \mathrm{~mL}$ of phosphate buffer saline solution (PBS, $0.01 \mathrm{M}$ phosphate buffer, $0.0027 \mathrm{M}$ potassium chloride and $0.137 \mathrm{M}$ sodium chloride, $\mathrm{pH} 7.4$ ) stirred at $60 \mathrm{rpm}$ at $37^{\circ} \mathrm{C}$. Aliquots of $500 \mu \mathrm{L}$ were withdrawn in predetermined time intervals $(0.0833,0.25,0.5,1,2,3,7$ and $8 \mathrm{~h}$ ) and the same volume of fresh medium was added to the solution in order to maintain the initial volume. Three replicates were performed in order to calculate the standard deviation error. The samples analyzed by UV-Vis spectroscopy at $242 \mathrm{~nm}$ (Shimazu UV 1601). Calculations of the amount of drug released took into account the replacement of aliquots with fresh medium.

\subsection{Water uptake}

The water uptake capability of the chitosan scaffolds prepared by freeze-drying was determined using a simple gravimetric method. Samples were weighed and immersed $10 \mathrm{~mL}$ of an isotonic solution at $\mathrm{pH}$ 7.4. The samples were placed in a water bath at $37^{\circ} \mathrm{C}$. After predetermined periods of time (1, 3, 5 and $7 \mathrm{~h}$ ) the samples were weighed in order to determine the water uptake of the scaffolds.

Water uptake was determined using the following equation:

$\%$ water uptake $=\frac{w_{\mathrm{w}}-w_{\mathrm{i}}}{w_{\mathrm{i}}} \times 100$

where $w_{\mathrm{w}}$ is the weight of the wet sample and $w_{\mathrm{i}}$ is the weight of the initial sample.

\section{Results and discussion}

In this study the possibility of preparing dexamethasone-loaded chitosan scaffolds with potential application in tissue engineering using supercritical fluid technology was evaluated. Chitosan scaffolds were prepared by freeze-drying after dissolution of the polymer in an acidic solution. Due to the high viscosity of this solution and the low solubility of dexamethasone in water, the conventional impregnation process does not lead to a homogeneous drug delivery system. Thus, supercritical fluid impregnation seems an interesting alternative to the conventional soaking method.

Supercritical fluid impregnation experiments were performed in a batch mode and different operational parameters were evaluated. The design of the experiments was 
Table 1

Summary of the operational conditions of the experiments performed.

\begin{tabular}{|c|c|c|c|c|c|}
\hline \#Experiment & Contact time $(\mathrm{h})$ & $P(\mathrm{MPa})$ & $T\left({ }^{\circ} \mathrm{C}\right)$ & $\mathrm{CO}_{2}$ density $\left(\mathrm{g} / \mathrm{cm}^{3}\right)^{\mathrm{a}}$ & \% Impregnation \\
\hline 1 & 3 & 8.0 & 35 & 0.414 & 0.37 \\
\hline 2 & & & 45 & 0.654 & 0.14 \\
\hline 3 & & & 55 & 0.772 & 0.05 \\
\hline 4 & & 10.0 & 35 & 0.248 & 0.14 \\
\hline 5 & & & 45 & 0.412 & 0.11 \\
\hline 6 & & 14.0 & 35 & 0.209 & 0 \\
\hline 7 & & & 45 & 0.326 & 0.01 \\
\hline 8 & 6 & 8.0 & 35 & 0.414 & 0.54 \\
\hline
\end{tabular}

a Carbon dioxide density was calculated using the using Phase Equilibria program, developed in Professor Gerd Brunner's department “Thermische Verfahrenstechnik" at the University of Hamburg-Harburg.

developed in order to study the parameters that affect the impregnation process. Experiments were carried out at pressures ranging from 8.0 bar up to $14.0 \mathrm{MPa}$ and temperatures from 35 up to $55^{\circ} \mathrm{C}$. Also, two different contact times during the impregnation process were studied. The depressurisation rate was kept constant in all experiments, as this is another variable that can influence the yield of impregnation. Table 1 summarizes the experiments performed and presents the percentage of drug impregnated in each one of the experiments.

The chitosan scaffolds prepared by freeze-drying are cylinders with an average diameter of 3.8 and $6.8 \mathrm{~mm}$ height. They did not suffer morphological changes after being subjected to high pressure carbon dioxide and this was confirmed by micro CT analysis. Chitosan scaffolds prior to the impregnation process were analysed. Results show that the scaffolds have a porosity of $\sim 87 \%$, which was the same value as observed for the scaffolds subjected to high pressure. The 3D model of the scaffold is presented in Fig. 3.

The resulting impregnated polymer scaffolds were cut into sections and characterized by SEM analysis. An example of the microstructure of an impregnated scaffold is presented in Fig. 4.

SEM analysis has shown that the drug is not deposited on the surface of the matrix and it is found in the bulk of the scaffold, in between the chitosan "leafs". Furthermore, no agglomeration of drug particles was found within the structure, instead discrete particles were observed dispersed through the chitosan scaffold. The high diffusivity of carbon dioxide in the polymer allows a homogeneous distribution of the drug into the core of the scaffold, which is one of the major advantages of the process. The diffusivity of carbon dioxide in a chitosan sphere was studied by Weinstein and Papatolis [31] and it is reported to be in the order of $10^{7} \mathrm{~m}^{2} / \mathrm{s}$, which is consistent with other reported studies on the diffusion of carbon dioxide in polymeric matrixes.

Impregnation efficiency results from a complex mechanism that involves interactions between the solute (dexamethasone), the carrier (carbon dioxide) and the matrix (chitosan scaffold). The relative strength of all binary interactions will contribute to the final partitioning of the solute between the mobile phase and the solid. As an example, a drug with a low solubility but exhibiting strong interactions with the matrix could be impregnated in a

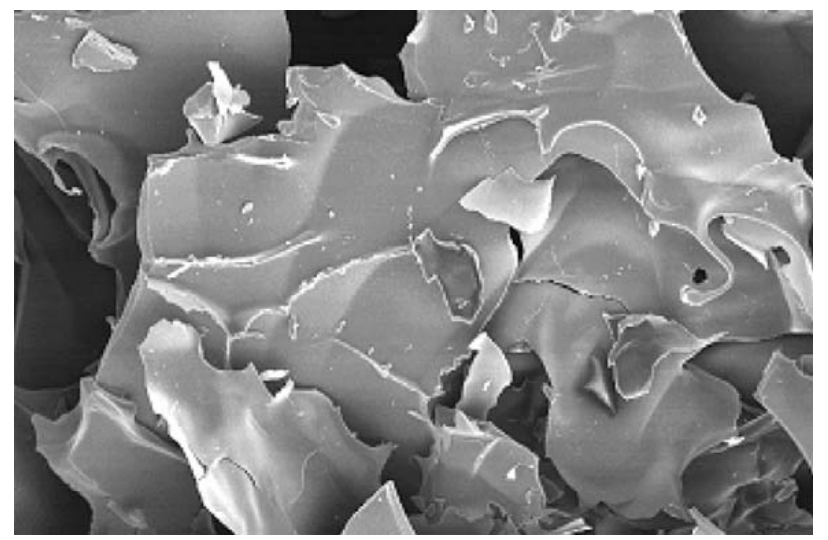

Fig. 4. SEM image a cross section of the chitosan scaffold loaded with dexamethasone at $8.0 \mathrm{MPa}$ and $55^{\circ} \mathrm{C}$.

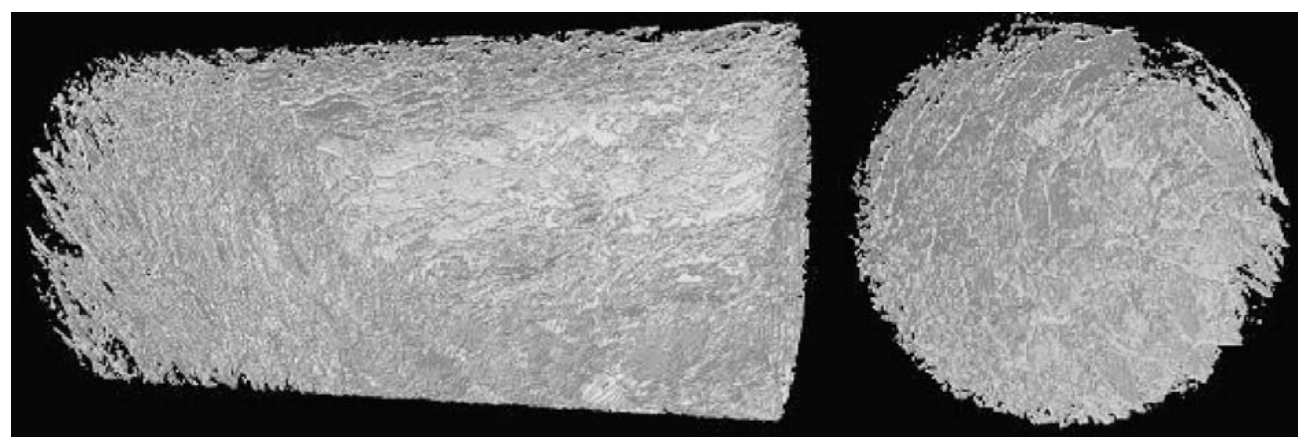

Fig. 3. 3D model of the chitosan scaffold obtained by micro-CT analysis. 
large extent; conversely, a drug with a higher interaction for the solvent compared to the solid will be poorly impregnated.

In this work we define the yield of impregnation as the relative quantity of drug in an impregnated scaffold, expressed as the ratio of drug weight/scaffold weight. The results presented are the average of at least three experiments and the maximum standard deviation error is $11 \%$.

The effect of the impregnation contact time, pressure and temperature are presented and discussed separately.

\subsection{Contact time effect}

The amount of drug impregnated can be tuned up to a certain extent to the desired values by changing the impregnation contact time. Increasing the impregnation time, there is also an increase in the percentage of drug impregnated in the polymeric matrix, as it would be expected (Fig. 5).

The supercritical fluid impregnation process is governed by thermodynamic and mass transfer relationships which are dependent, in a complex manner, on the carbon dioxide pressure and operating temperature [32,33]. Pressure and temperature not only affect the solubility of the drug in the carbon dioxide but also influence the sorption degree of the polymer, i.e., the amount of carbon dioxide that is can be solubilized in the polymeric matrix. Three different interactions, between polymer- $\mathrm{CO}_{2}$, drug- $\mathrm{CO}_{2}$ and drug-polymer are relevant for the understanding of the mechanisms that govern this process. This is not always easy as the determination of the partition coefficients between the substances involved in the impregnation process is difficult to be calculated.

Gong and co-workers [34] have reported the impregnation of indomethacin into chitosan matrixes using supercritical fluid technology. FTIR analysis of the matrixes has shown that the aliphatic carbonyl group of indomethacin interacts with the $\mathrm{NH}_{2}$ group of chitosan. Due to the low drug loading of our samples FTIR results performed to the impregnated scaffolds were inconclusive. However, from the chemical structure of dexamethasone and chitosan we can infer that possible hydrogen bonds are established between the hydroxyl groups of the drug and the amine groups of the polymer.

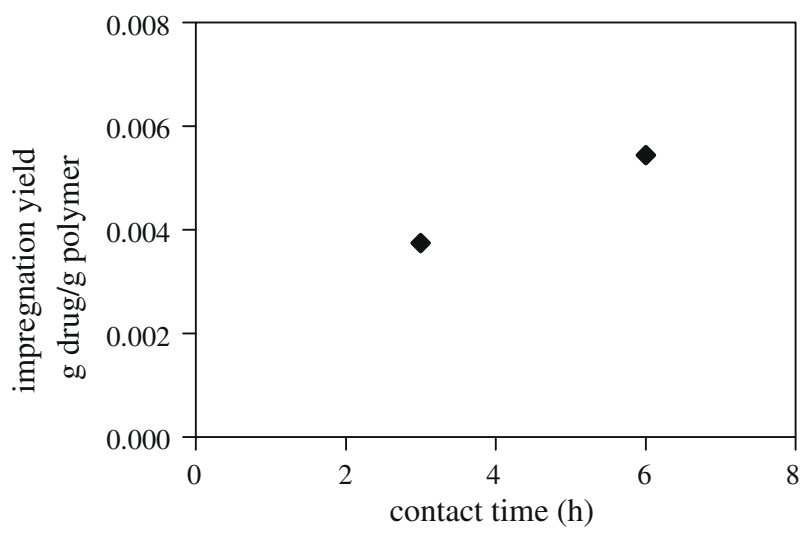

Fig. 5. Effect of contact time on the percentage of impregnation.
Kazarian and co-workers [25,35,36] distinguish two mechanisms of impregnation assisted by supercritical fluids. The first mechanism corresponds to a simple deposition of the compound when the fluid leaves the swollen matrix. In this case, the solute is solubilized in carbon dioxide and the polymer is exposed to this solution for a predetermined period followed by depressurization of the system. When the system is depressurised, carbon dioxide molecules quickly leave the polymer matrix, leaving the solute trapped inside. As reported by Kazarian, this situation involves mostly solute with a relatively high solubility in the fluid and it is specific to impregnation carried out on a matrix subjected to swelling upon exposure to the supercritical fluid. The second effect, not specific to supercritical fluids, corresponds to chemical interactions (like van der Waals interactions) between the solute and the matrix, that would favour the preferential partitioning of the solute with the polymer phase. According to our results and for the particular case presented in this work, we believe the second mechanism described is the one controlling the impregnation process.

\subsection{Pressure effect}

The effect of pressure on the impregnation yield was studied for different temperatures. In Fig. 6a, this effect is shown.

Comparing isotherms of the experiments performed at different pressures we can conclude that higher pressures lead to lower impregnation yields.
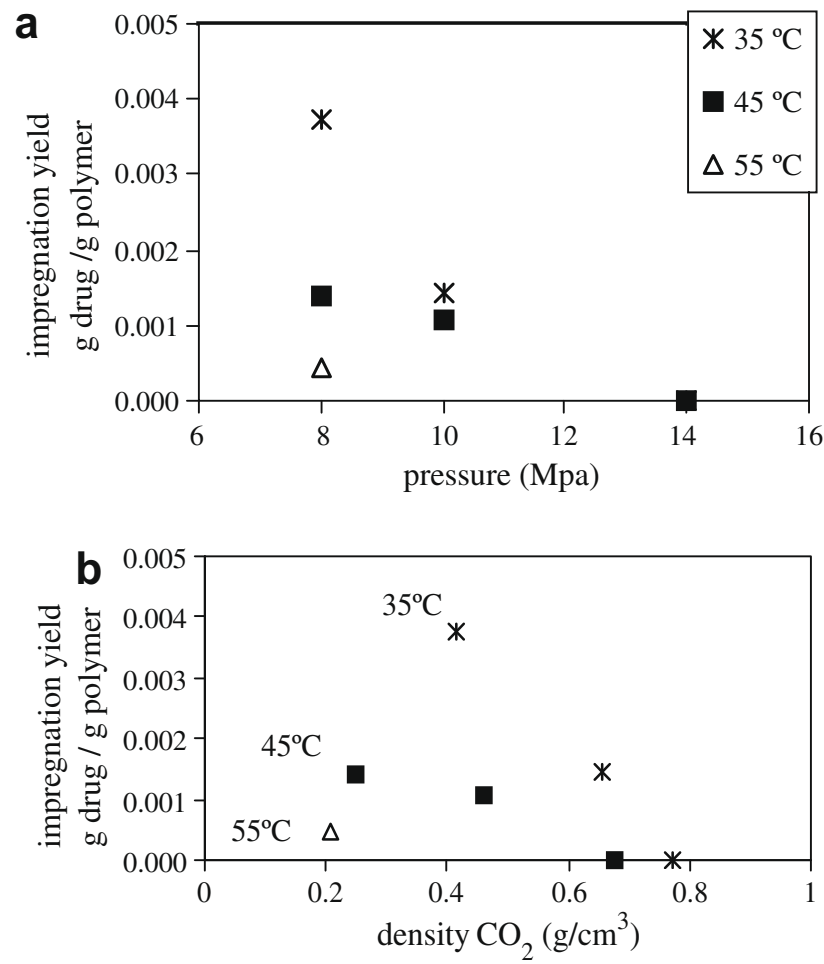

Fig. 6. (a) Effect of pressure on the percentage of impregnation, note that the data points of the experiments performed at $35^{\circ} \mathrm{C}$ and $45^{\circ} \mathrm{C}$ at 14.0 MPa are superposed. (b) Density and temperature effect on the percentage of impregnation of the scaffolds. 
The effect of pressure is intimately related with the sorption degree of the polymer in the presence of carbon dioxide. Weinstein and Papatolis [31] report the sorption of supercritical carbon dioxide in chitosan spheres for different operating conditions. According to this study, the solubility of $\mathrm{CO}_{2}$ in the polymer increased as the operating density and temperature increased. The work presented can be extrapolated to our scaffolds and we can assume that chitosan is able to dissolve carbon dioxide and swell in the presence of this solvent. A pressure increase leads to an increase in sorption degree of the polymer, for a given temperature. Furthermore, the maximum sorption degree is achieved after approximately $3 \mathrm{~h}$ of exposure, which was the time set for the impregnation experiments. We can then conclude that the effect of pressure on the impregnation yield represents also the trend of the yield of impregnation versus the sorption degree of the polymer. Lower sorption degrees, therefore lower swelling of the matrix will favour the interaction between dexamethasone and the polymeric matrix leading to a higher yield of impregnation. From the results obtained we can then conclude that higher impregnation yields are achieved at lower operational pressures.

Moreover, the pressure also affects the drug solubility in carbon dioxide. For an isothermal pressure increase, the solubility of the drug in the supercritical fluid increases. This can be easily explained in physical terms. Density rises with increasing pressure, which means that the intermolecular mean distance of the molecules decreases and the specific interactions between the solute and the solvent increase, leading to a higher solubility. As a consequence, the partition coefficient of the drug towards the polymeric matrix decreases and lower yields of impregnation are achieved for the experiments performed at higher pressures.

\subsection{Temperature and density effect}

The temperature plays two different roles regarding its effect on the impregnation process. Whereas the solubility of the drug increases with increasing temperature, after the crossover region, the sorption degree of the polymer is lower for higher temperatures.

In the case of the drug solubility, temperature influences not only solid-vapour pressure but also solvent density and intermolecular interactions in the fluid phase [37]. Regarding the sorption of the polymeric matrix, it has been demonstrated that carbon dioxide interacts with the polymer most probably through Lewis acid-base interactions $[38,39]$. These interactions have an exothermic nature, which might explain the fact that the solubility of carbon dioxide in the polymer matrix decreases with increasing temperature [40].

From the experiments carried out in this work we can conclude that the impregnation yield decreases for an isobaric increase in temperature (Fig. 6b).

Higher densities (or higher temperatures) favour the interactions between dexamethasone and carbon dioxide and are detrimental to the bonding forces between the solute and the matrix, therefore at higher temperatures the impregnation yield is lower $[41,42]$.
The results obtained agree with the literature data available for this kind of impregnation process and demonstrate that although the solubility of the drug in the supercritical solvent might not be very high, it does not compromise the impregnation process. In the same way, the sorption degree of the polymer should not be very large otherwise the interactions between the solute and the matrix are not promoted resulting in a poorly impregnated polymer.

In the case of impregnation of chitosan scaffolds with dexamethasone, and for the operating conditions tested the higher impregnation yield was achieved for scaffolds prepared at $8.0 \mathrm{MPa}$ and $35^{\circ} \mathrm{C}$, i.e., lower pressures and temperatures.

\subsection{Drug release profile}

The drug release profile was evaluated for sample 2 prepared at 80 bar and $45^{\circ} \mathrm{C}$ and it is presented in Fig. 7. In this figure it is shown the amount of drug released as well as the concentration of drug in solution.

Chitosan is a hydrophilic polymer and therefore has a very high water uptake capability. We evaluated the water uptake of the scaffolds prepared by freeze-drying in order to have a better understanding on the mechanism of drug release from these devices (Fig. 8).

The macroscopic observation of the chitosan scaffolds allows us to conclude that chitosan is also a highly swellable polymer. The diffusion of water into the polymeric matrix facilitates the diffusion of the drug out of the polymeric matrix into the physiological solution and therefore nearly $90 \%$ of the drug is released after $2 \mathrm{~h}$.

Chitosan scaffolds are shown to be suitable as controlled release devices able to incorporate and release active molecules. The impregnation of dexamethasone has two main purposes as it is not only a steroidal anti-inflammatory agent, but it also induces effectively differentiation of bone marrow stem cells towards osteoblastic lineage. For tissue engineering of bone from stem cells, medium composition can guide differentiation along the osteogenic lineage. Glucocorticoids, such as dexamethasone, are added routinely in osteogenic medium as they show to have stimulatory effects on skeletal cells. It has also been suggested that the exposure of stem cells to dexamethasone may be effective in inducing and maintaining the

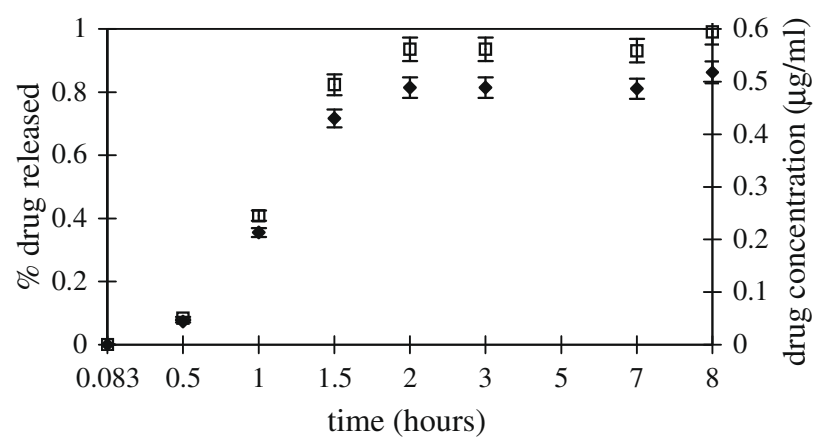

Fig. 7. Dexamethasone release $(\square)$ and concentration of dexamethasone in solution $(\checkmark)$ from the scaffold prepared at $8.0 \mathrm{MPa}$ and $45^{\circ} \mathrm{C}$. 


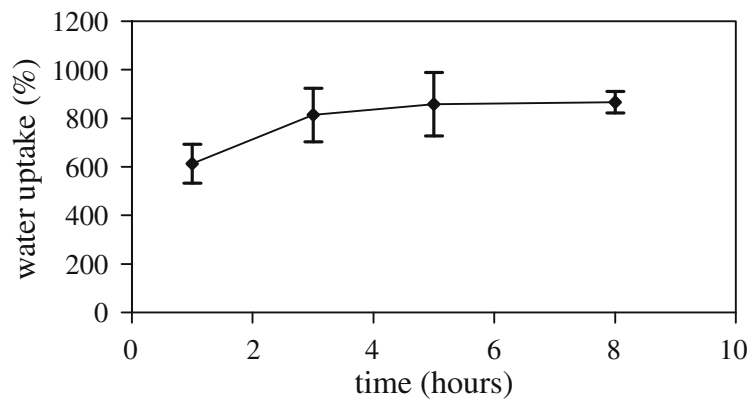

Fig. 8. Water uptake of the chitosan scaffolds prepared by freeze drying.

osteoblastic phenotype [43]. Several studies in the literature report the in vitro osteogenic differentiation of purified, culture-expanded human marrow stromal cells, therefore, the preparation of a scaffold able to release an active agent at a controlled rate, with the appropriate concentration is important.

We can conclude from the results obtained that although the impregnation yield achieved using supercritical fluid technology is apparently not very high, $\sim 0.0014 \mathrm{~g}$ dexamethasone/g polymer, it still leads to concentrations higher than the ones described for the preparation of osteogenic medium (between 10 and $20 \mathrm{nM}$ ) [44].

\section{Conclusions}

Chitosan scaffolds were successfully impregnated with dexamethasone. Different experimental conditions were tested and the results obtained suggest that the best impregnating conditions for this system are those involving low temperatures and pressures (8.0 MPa and $35^{\circ} \mathrm{C}$ ), which at the same time correspond to a lower solubility of the drug in the supercritical fluid and a low swelling of the polymeric matrix.

Impregnation efficiency results from a complex mechanism that involves interactions between the solute, the carrier and the matrix. The relative strength of all binary interactions will contribute to the final partitioning of the solute between the mobile phase and the solid. In the case of the polymer and drug studied in this work, results suggest that the interactions between the drug and the fluid phase are stronger than the ones of the drug to the polymeric matrix. From the chemical structure of the substances involved we can infer that hydrogen bonds can be established between the hydroxyl groups of dexamethasone and the amine groups of chitosan. Therefore, lower solvent densities favour the impregnation process.

The release of dexamethasone from chitosan scaffolds presented a sustained profile and we can conclude that although the yield of impregnation using supercritical fluid technology is not very high it leads to drug concentrations appropriate for applications in tissue engineering.

\section{Acknowledgment}

Ana Rita C. Duarte is grateful for financial support from Fundação para a Ciência e Tecnologia through the SFRH/ BPD/34994/2007 Grant.

\section{References}

[1] Malafaya PB, Silva GA, Baran ET, Reis RL. Drug delivery therapies I: general trends and its importance on bone tissue engineering applications. Curr Opin Solid State Mater Sci 2002;6(4):283-95.

[2] Malafaya PB, Silva GA, Baran ET, Reis RL. Drug delivery therapies II: strategies for delivering bone regenerating factors. Curr Opin Solid State Mater Sci 2002;6(4):297-312.

[3] Gomes ME, Reis RL. Biodegradable polymers and composites in biomedical applications. from catgut to tissue engineering. Part I: available systems and their properties. Int Mater Rev 2004;49(5):261-73.

[4] Gomes ME, Reis RL. Biodegradable polymers and composites in biomedical applications. From catgut to tissue engineering. Part II: systems for temporary replacement and advanced tissue regeneration. Int Mater Rev 2004;49(5):274-85.

[5] Malafaya PB, Silva GA, Baran ET, Reis RL. Drug delivery therapies I, general trends and its importance on bone tissue engineering applications. Curr Opin Solid State Mater Sci 2002;6:283-95.

[6] Malafaya PB, Silva GA, Reis RL. Natural-origin polymers as carriers and scaffolds for biomolecules and cell delivey in tissue engineering applications. Adv Drug Del Rev 2007;59(4-5):207-33.

[7] Green D, Walsh D, Yang X, Mann S, Oreffo ROC. Stimulation of human bone marrow stromal cells using growth factor encapsulated calcium carbonate porous microspheres. J. Mater Chem 2004;14:2206-12.

[8] Eroglu H, Kas HS, Oner L, Turkoglu OF, Akalan N, Sargon MF, Ozer N. The in-vitro and in-vivo characterization of PLGA:L-PLA microspheres containing dexamethasone sodium phosphate. J Microencapsul 2001;18:603-12.

[9] Yoon JJ, Kim JH, Park TG. Dexamethasone-releasing biodegradable polymer scaffolds fabricated by a gas-foaming/salt-leaching method. Biomaterials 2003;24:2323-9.

[10] Gomes M, Azevedo H, Malafaya PB, Silva SS, Oliveira JM, Silva GA, Sousa R, Mano JF, Reis RL. Natural polymers in tissue engineering applications. Tissue Eng 2008:145-92.

[11] Santos TC, Marques AP, Silva SS, Oliveira JM, Mano JF, Castro AG, Reis RL. In vitro evaluation of the behaviour of human polymorphonuclear neutrophils in direct con tact with chitosanbased membranes. J Biotechn 2007;132(2):218-26.

[12] Prabaharan M, Mano JF. Chitosan-based particles as controlled delivery systems. Drug Deliv 2005;12:41-57.

[13] Tuzlakoglu K, Alves CM, Mano JF, Reis RL. Production and characterization of chitosan fibers and 3-D fiber mesh scaffolds for tissue engineering applications. Macromol Biosci 2004;4(8):811-9.

[14] Shi J, Alves NM, Mano JF. Chitosan coated alginate beads containing poly( $N$-isopropylacrylamide) for dual-stimuli-responsive drug release. J Biomed Mater Res Part B 2008;84B(2):595-603.

[15] Prabaharan M, Rodriguez-Perez MA, de Saja JA, Mano JF. Preparation and characterization of poly(L-lactic acid)-chitosan hybrid scaffolds with drug release capability. J Biomed Mater Res Part B 2007;81B(2):427-34.

[16] Denkbas EB, Ottenbrite RM. Perspectives on: Chitosan drug delivery systems based on their geometries. J Bioactive Compatible Polym 2006;21:351-68.

[17] Oungho K, Müller BW. Chitosan spomges as sustained release drug carriers. Int J Pharm 1997;156:229-37.

[18] Mi F-L, Shyu S-S, Wu YB, Lee S-T, Shyong J-Y, Huang R-N. Fabrication and characterization of a sponge-like asymmetric chitosan membrane as a wound dressing. Biomaterials 2001;22:165-73.

[19] Braga MEM, Pato MTV, Costa Silva HSR, Ferreira EI, Gil MH, Duarte CMM, Sousa HC. Supercritical solvent impregnation of ophthalmic drugs on chitosan derivatives. J Supercrit Fluids 2008;44:245-57.

[20] Temtem M, Casimiro T, Mano JF, Aguiar-Ricardo A. Green synthesis of a temperature sensitive hydrogel. Green Chem 2007;9(1):75-9.

[21] Kikic I, Vecchione F. Supercritical impregnation of polymers. Curr Opin Solid State Mater Sci 2003;7:399-405.

[22] Elvira C, Fanovich A, Fernández M, Fraile J, Román JS, Domingo C. Evaluation of drug delivery characteristics of microspheres of PMMA-PCL-Cholesterol obtained by supercritical $\mathrm{CO}_{2}$ impregnation and by dissolution-evaporation techniques. J Control Rel 2004;99:231-40.

[23] Kikic I, Sist P. Applications of supercritical fluids to pharmaceuticals: controlled drug delivery systems, supercritical fluids: fundamentals and applications. In: Kiran E, Debenedetti PG, Peters CJ, editors. Proceedings of the 2nd NATO ASI on supercritical fluids, NATO Science series. Dordrecht, Netherlands: Kluwer Academic Publishers.; 2000. p. 291-306. 
[24] Berens AR, Huvard GS, Korsmeyer RW, Kunig FW. Application of compressed carbon dioxide in the incorporation of additives into polymers. J Appl Polym Sci 1992;46:231-42.

[25] Kazarian SG. Supercritical Fluid Impregnation of Polymers for Drug Delivery. In: Supercritical Fluid Technology for Drug Product Development. New York: Marcel Dekker Inc.; 2004. p. 343.

[26] Mano JF. Viscoelastic properties of chitosan with different hydration degrees as studied by dynamic mechanical analysis. Macromol Biosci 2008;8:69-76.

[27] Silva SS, Oliveira JM, Mano JF, Reis RL. Physicochemical characterization of novel chitosan-soy protein/TEOS porous hybrids for tissue engineereing applications. Adv Mater Forum III 2006;514-516:1000-4.

[28] Oliveira JM, Rodrigues MT, Silva SS, Malafaya PB, Gomes ME, Viegas CA, et al. Novel hydroxyapatite/chitosan bilayered scaffold for osteochondral tissue-engineering applications: Scaffold design and its performance when seeded with goat bone marrow stromal cells. Biomaterials 2006;27(32):6123-37.

[29] Duarte ARC, Simplicio AL, Vega-González A, Subra-Paternault P, Coimbra P, Gil MH, Sousa HC, Duarte CMM. Impregnation of an intraocular lens for ophthalmic drug delivery. Curr Drug Deliv 2008;5(2):102-7.

[30] Duarte ARC, Simplicio A, Vega-González A, Subra-Paternault P, Coimbra P, Gil MH, Sousa HC, Duarte CMM. Supercritical fluid impregnation of biocompatible polymer for ophthalmic drug delivery. J Supercrit Fluids 2007;42(3):373-7.

[31] Weinstein RD, Papatolis J. Diffusion of liquid and supercritical carbon dioxide into a chitosan sphere. Ind Eng Chem Res 2006;45:8651-5.

[32] Shen Z, Huvard GS, Warrier CS, McHugh M, Banyasz JL, Mishra MK. $\mathrm{CO}_{2}$ assisted fiber impregnation. Polymer 2008;49:1579-86.

[33] Lucas S, Calvo MP, García-Serna J, Palencia C, Cocero MJ. Two parameter model for mass transfer processes between solid matrixes and supercritical fluids: analytica solution. J Supercrit Fluids 2007;41:257-66.
[34] Gong K, Darr JA, Rehman IU. Supercritical assisted impregnation of indomethacin into chitosan thermosets for controlled release applications. Int J Pharm 2006;315:93-8.

[35] Kazarian SG. Polymer processing with supercritical fuids. Polym Sci Ser C 2000;42(1):78-101.

[36] Kazarian SG, Martirosyan GG. Spectroscopy of polymer/drug formulations processed with supercritical fluids: in situ ATR-IR and Raman study impregnation of ibuprofen into PVP. Int J Pharm 2002;232:81-90.

[37] Duarte ARC, Coimbra P, Sousa HC, Duarte CMM. Solubility of flurbiprofen in supercritical carbon dioxide. J Chem Eng Data 2004;49(3):449-52.

[38] Brantley NH, Kazarian SG, Eckert CA. In situ FTIR measurement of carbon dioxide sorption into poly(ethylene terephthalate) at elevated pressures. J Appl Polym Sci 2000;77:764-75.

[39] Kazarian SG, Vincent MF, West BL, Eckert CA. Partitioning of solutes and cosolvents between supercritical $\mathrm{CO}_{2}$ polymer phases. J Supercrit Fluids 1998;13(1-3):107-12.

[40] Duarte ARC, Martins C, Coimbra P, Gil MH, Sousa HC, Duarte CMM. Sorption and diffusion of supercritical carbon dioxide in a biocompatible polymer. J Supercrit Fluids 2006;38(3): 392-8.

[41] Subra P, Vega-Bancel A, Reverchon E. Breakthrough curves and adsorption isotherms of terpene mixtures in supercritical carbon dioxide. J Supercrit Fluids 1998;12:43-57.

[42] Diankov S, Barth D, Vega-González A, Pentchev I, Subra-Paternault P. Impregnation isotherms of hydroxybenzoic acid on PMMA in supercritical carbon dioxide. J Supercrit Fluids 2007;41:164-72.

[43] Jaiswal N, Haynesworth SE. Osteogenic differentiation of purified, cultured-expanded human mesenchymal stem cells in vitro. J Cell Biochem 1997;64(2):295-312.

[44] Hoffman S, Kaplan D, Vunjak-Novakovic G, Meinel L. Tissue engineering of bone. In: Vunjak-Novakivic G, Freshney RI, editors. Culture of cells for tissue engineering. New Jersey: John Wiley \& Sons, Inc., Hoboken; 2006. 